\title{
Mothers' Time With Infant and Time in Employment as Predictors of Mother-Child Relationships and Children's Early Development
}

\author{
Aletha C. Huston and Stacey Rosenkrantz Aronson \\ University of Texas at Austin
}

\begin{abstract}
This study tested predictions from economic and developmental theories that maternal time with an infant is important for mother-child relationships and children's development, using time-use diaries for mothers of 7- to 8-month-old infants from the National Institute of Child Health and Human Development Study of Early Child Care $(N=1,053)$. Employment reduced time with infants, but mothers compensated for some work time by decreasing time in other activities. With family and maternal characteristics controlled, time with infants predicted high Home Observation for Measurement of the Environment (HOME) scores and maternal sensitivity, but bore little relation to children's engagement with mothers, secure attachment, social behavior, or cognitive performance from 15 to 36 months. Mothers who spent more time at work had higher HOME scores. Maternal time with infants may reflect maternal characteristics that affect both time allocation and maternal behavior.
\end{abstract}

Mothers' time with their infants and young children is a central construct in both economic and developmental theories of family influences on children's development. Economic theories (e.g., Becker, 1981; Coleman, 1988) assume that time is a resource or commodity that parents invest in their children. Time with children provides social capital that creates human capital for at least two reasons. First, one element of social capital is trustworthiness of a social context, which a consistent, available caregiver may provide. Second, time is a prerequisite for parents to provide intellectual stimulation and social interactions for their children. According to Coleman (1988), social capital in the family requires both time and attention to the child during that time. Economic theories of the family are generally discussed in relation to the development of older children, but they can also be applied to very young children.

Developmental hypotheses about the effects of maternal time with their infants are drawn from theories of attachment and early social and cognitive stimulation (Belsky, 2001; Brazelton, 1986; Sroufe,

We are grateful to the National Institute of Child Health and Human Development Early Child Care Research Network for designing and carrying out the data collection, and to Young Chang for helpful comments on earlier drafts. This research was supported in part by a grant from the National Institutes of Health (2V10 HD25430-11) to the University of Kansas with a subcontract to the University of Texas at Austin, and by funding from the University of Texas at Austin.

Correspondence concerning this article should be addressed to Aletha C. Huston, Department of Human Ecology, University of Texas at Austin, 1 University Station A2700, Austin, TX 787120141. Electronic mail may be sent to achuston@mail.utexas.edu.
1988; Vaughn, Gove, \& Egeland, 1980). According to attachment theory, the infant forms a working model of secure social relationships on the basis of experience with a sensitive, responsive, and predictable attachment figure, usually the mother. Extended hours of separation may disrupt this process because mothers have fewer opportunities to learn their infants' signals and to develop appropriate reciprocal interactions, and infants may experience their mothers' presence as sporadic and unpredictable. Few investigations have measured time directly in relation to attachment. In one study of a small sample, mothers' reports of time with their infant at 3 months of age were positively related to attachment security at 1 year (Cox, Owen, Henderson, \& Margand, 1992), but there were no differences in attachment security as a function of maternal time with their infants at 7 to 8 months in analyses with a larger sample by Booth, Clarke-Stewart, Vandell, McCartney, and Owen (2002). Mother-child time may also be a necessary if not sufficient condition for stimulation of cognitive activities, language, and positive social interactions.

\section{Maternal Employment as a Proxy for Time}

As the number of employed mothers with young children has risen dramatically over the last several decades, many have expressed concern that loss of maternal time will affect children's development

(C) 2005 by the Society for Research in Child Development, Inc. All rights reserved. 0009-3920/2005/7602-0011 
negatively, particularly during the 1st year of life. In much of the literature investigating maternal employment, there is an implicit or explicit assumption that maternal employment affects both socioemotional and cognitive development because it reduces mothers' time with their children, which leads to less sensitive mother-child relationships or less language and cognitive stimulation (see Belsky, 2001; Coleman, 1988; Desai, Chase-Lansdale, \& Michael, 1989; Gottfried, Gottfried, Bathurst, \& Killian, 1999; Hoffman \& Youngblade, 1999; Huston, 2002; Vaughn et al., 1980; Zaslow, McGroder, Cave, \& Mariner, 1999). Possible deleterious effects of employment during the 1st year of life have received particular attention in some recent investigations (e.g., Waldfogel, Han, \& Brooks-Gunn, 2002).

Employment and mother-child time. Time diaries of large representative samples show that, on average, employed women spend less time caring for their children than do nonemployed women, but there are smaller differences in child care time than would be expected based on work time (Almeida, 1997; Bryant \& Zick, 1996b; Gershuny \& Robinson, 1988; Robinson \& Godbey, 1997). In time-use diaries, care of children is coded when mothers name that activity when asked what they were doing; it does not include all time spent with children while mothers are engaged in other activities. For example, among 3- to 12-year-olds, the only consistent relation between maternal employment and children's time allocation is that children of employed mothers spend more time in nonmaternal child care (Bianchi, 2000; Hofferth \& Sandberg, 2001). Employed women apparently compensate for their absence by spending more time with their children during nonwork hours (Easterbrooks \& Goldberg, 1985; Hill \& Stafford, 1985; Nock \& Kingston, 1988; Zaslow, Pederson, Suwalsky, Cain \& Fivel, 1985).

Mothers' time with children declines as children get older, but most of the large time-use studies do not focus on infancy (e.g., Timmer, Eccles, \& O'Brien, 1984). One exception is an earlier analysis of two groups of mothers in the National Institute of Child Health and Human Development (NICHD) Study of Early Child Care using child care time as a proxy for maternal employment. With adjustments for demographic differences, mothers who used no regular nonmaternal child care between birth and 6 months spent $38.3 \mathrm{hr}$ a week with their infants compared with $26.1 \mathrm{hr}$ for mothers who used more than $30 \mathrm{hr}$ a week of nonmaternal care (Booth et al., 2002).

Quality of mother-infant time. Both economic and developmental theories predict that how mothers spend time with their children is important. Although quality time is difficult to operationalize, most people agree that time when the parent is attending to and interacting with the child is probably of higher quality than when the parent is attending to other people or tasks (Coleman, 1988). There is some evidence that employed women spend a higher proportion of their child care time in direct interaction with their children than is true for nonemployed women (Ahnert, Rickert, \& Lamb, 2000; Booth et al., 2002; Bryant \& Zick, 1996a; Nock \& Kingston, 1988).

\section{Maternal Employment and the Mother-Infant Relationship}

Mother-child interaction. Positive mother-child relationships are indicated by maternal sensitivity and responsiveness and by infant engagement and positive affect during their interactions. Most investigations that compare employed and nonemployed mothers find no differences in maternal sensitivity or responsiveness (e.g., Owen \& Cox, 1988; Schubert, Bradley-Johnson, \& Nuttal, 1980; Stifter, Coulehan, \& Fish, 1993; Stith \& Davis, 1984). In fact, there is some evidence that employed mothers are more interactive, sensitive, and positive toward their infants and toddlers (Broom, 1998; Crockenberg \& Litman, 1991; Zaslow et al., 1985). However, in one study, women who returned to employment sooner after giving birth displayed more negative affect and behavior toward their infant than did those who remained home longer before returning to paid employment (Clark, Hyde, Essex, \& Klein, 1997). In another study, short maternity leaves were associated with more maternal depression and less preoccupation and knowledge about the infant (Feldman, Sussman, \& Zigler, 2004). Analyses of the NICHD Study of Early Child Care show that mothers of children in extensive hours of child care were less sensitive than mothers of children in fewer hours of care, although the effects attenuated after age 3 (NICHD Early Child Care Research Network, 1999, 2003b).

Home environment. Mothers' time away from home may influence the quality of the home environments that families create for their children. In general, however, the homes of employed and nonemployed women do not differ on the Home Observation for Measure of the Environment (HOME) scale, which includes assessments of the quality of the home environment and maternal behavior toward the infant (Brooks-Gunn, Han, \& Waldfogel, 2002; Gottfried, Gottfried, \& Bathurst, 1988; Gottfried et al., 1999).

Attachment security. Early maternal employment, and its proxy, nonmaternal care, are inconsistently 
related to attachment security. Some investigations have shown that infants with employed mothers are more likely to be insecurely attached (Schwartz, 1983; Vaughn et al., 1980), but others have reported no association between early maternal employment and mother-infant attachment (Chase-Lansdale \& Owen, 1987; Easterbrooks \& Goldberg, 1985; Owen, Easterbrooks, Chase-Lansdale, \& Goldberg, 1984; Stifter et al., 1993). Similarly, some studies find that nonmaternal care in the 1st year of life is associated with increased likelihood of insecure attachment, but others have failed to replicate this finding (see Lamb, 1997, for review). The NICHD Study of Early Child Care found no overall association of nonmaternal care with attachment security, but children whose mothers were insensitive and who experienced extensive child care were more likely to manifest insecure attachment at both 15 months and 3 years of age (NICHD Early Child Care Research Network, 1997a, 2001).

Social behavior. A strong mother-child relationship forms a basis for the child's internalization of maternal expectations and values (Kochanska \& Thompson, 1997). If reduced mother-child time during infancy interferes with the mother-child bond, it might also lead to more noncompliance and behavior problems, particularly as children move beyond infancy. In earlier analyses of the NICHD Study of Early Child Care, there were no relations of time in child care to compliance and defiance in observed interactions with the mother or with an adult administering a test, nor to mothers' ratings of social skills and behavior problems at ages 2 and 3 (NICHD Early Child Care Research Network, 1998). By age 4 and kindergarten, however, cumulative quantity of child care was associated with caregiverand teacher-reported behavior problems and less strongly with maternal reports of problems (NICHD Early Child Care Research Network, 2003a).

Cognitive outcomes. Reduced mother-child time might affect cognitive and language development if it leads to reduced opportunities for interchange and stimulation. In longitudinal analyses, early maternal employment is inconsistently associated with later cognitive performance (Belsky \& Eggebeen, 1991; Brooks-Gunn et al., 2002; Greenstein, 1995; Han et al., 2001; Harvey, 1999; Vandell \& Corasaniti, 1990; Vandell \& Ramanan, 1992). Waldfogel et al. (2002) reported negative associations between cognitive outcomes and maternal employment that begins before age 9 months, and positive associations between these outcomes and maternal employment in the 2nd and 3rd years for non-Hispanic White, but not African American or Hispanic, children.
Demographic and Psychological Differences Associated

With Parents' Time Allocation and With Maternal

Employment

Parents' allocation of time to their children may reflect their own characteristics and priorities. Mothers who are more educated, more sensitive to their infants' needs, and more stimulating to their children may also spend more time with their infants. That is, time may not be the cause of maternal sensitivity and inclination to interact with the child but may instead be a reflection of these maternal characteristics. Both family structure and education predict mothers' time allocations. Women with larger families divide their available child care time among more children. College-educated women spend more time playing with, reading to, and teaching their children than do women with less education (Hill \& Stafford, 1985; Timmer et al., 1985). They do not decrease the amount of time they spend with their children as a function of the amount of time others care for them, although less educated women do (Hill \& Stafford, 1985; Leibowitz, 1974). Some of these same characteristics affect maternal employment. For example, employed mothers are generally better educated, have fewer children, have more family income, and believe that maternal employment is not harmful to children (Hoffman \& Youngblade, 1999).

\section{Research Questions}

Despite the theoretical importance of the time mothers and infants spend together, most of the earlier research has measured the time they spend apart, assuming that time with children is reduced in direct proportion to the mother's time in employment or the child's time in nonmaternal care. In this report we focus on shared mother-infant time directly. The analyses are based on the time-use data used by Booth et al. (2002) and build on their findings in the following ways. First, by examining the entire sample rather than extreme groups (the Booth et al., 2002, sample constituted $28 \%$ of the mothers completing time-use diaries), we can assess the whole range of work and child care times continuously. Variations in time use within extreme groups may have restricted ranges that obscure relations of maternal time to other variables, and the extremegroup approach does not address the many existing combinations of work and home responsibilities. We also include mothers without partners, controlling for the presence of a partner; therefore, the sample represents a wider range of families. Second, we 
examine time in employment rather than the infant's time in child care; time at work is included in the analyses to determine its effects independently of time with the child. If something about the amount of employment other than its effect on mother-child time is an important determinant of the mother and child outcomes assessed, work time should account for some of the variation in the outcomes. Thid, we examine predictors of maternal time with infants and in employment, not only to control for selection bias but also to illuminate the maternal characteristics associated with different time-allocation patterns. Fourth, we extend the analysis beyond 15 months to 3 years to determine whether any relations of time use in infancy to mother-child relationships endure well beyond infancy, and we examine children's social and cognitive development at 2 and 3 years to determine whether time with the mother predicts compliance, self-control, behavior problems, or language development in the preschool years. Finally, like Booth et al., we examine time in instrumental care and social interaction separately, but we also examine the proportion of available time (i.e., nonwork time) devoted to the child. We ask three questions:

1. How is maternal employment related to the amount of time mothers spend engaged in instrumental care and social interaction with their infants?

2. What demographic and personal characteristics of mothers predict time with children and time in employment?

3. Does mothers' time with their infants predict home environment quality and positive mother-infant relationships? Does it predict children's compliance, self-control, behavior problems, or cognitive and language development over the first 3 years of life? Do instrumental care and social interaction predict differently?

\section{Method}

\section{Participants}

The initial sample from the NICHD Study of Early Child Care consisted of 1,364 families recruited from 10 sites around the United States when infants were born. The sampling plan and selection are described in NICHD Early Child Care Research Network (1997b). Although the sampling plan excluded mothers under 18, mothers who did not speak English, and low-birth-weight babies, the sample was diverse, including $24 \%$ ethnic minority children, $11 \%$ mothers without a high school education, and $14 \%$ single mothers. The recruited families were demographically similar to the population of eligible families in the catchment areas. Of the 1,364 families who began the study, 1,053 formed the sample for the present analysis. In our sample, $52 \%$ of the children were male; the average maternal education was 14.4 years; the average family income-to-needs ratio was 3.71; and the ethnic distribution of mothers was $81 \%$ non-Hispanic White, $11 \%$ non-Hispanic African American, 4\% Hispanic, and 4\% other.

\section{Data}

Data included in this report were collected from the time the child was age 1 month to age 36 months. At child ages 1, 6, 15, 24, and 36 months, interviewers visited families at home and, with the exception of 1 and 24 months, administered the HOME scale. At 6 and 15 months, infants and mothers were videotaped in semistructured interactions at home, and at 24 and 36 months, they were videotaped in a laboratory. At 7 months, mothers completed time diaries over the telephone. Children's intellectual and social development was assessed at ages 15, 24, and 36 months.

\section{Time Use}

When the infants were 7 months old, mothers completed two telephone interviews using a time diary procedure (Juster \& Stafford, 1985). In each call, the mother reported her activities for the previous 24-hr period sequentially, from midnight to midnight. Interviewers recorded the length of each activity and whether the mother was engaged in any other activities at the same time (secondary activities). Most mothers were interviewed for 1 weekday and 1 weekend day $(n=987)$. If the participant could not be reached for a weekend day, she was interviewed about a 2 nd weekday $(n=48)$ and vice versa $(n=18)$.

For mothers who were employed $(n=580)$, interviewers also selected the days to include 1 workday and 1 nonworkday. For most employed mothers, the workday was a weekday and the nonworkday was a weekend day $(n=513)$. If the mother worked on the weekend, a weekday on which she did not work was selected as the 2 nd day $(n=29)$. In a few cases, the mother worked both the weekday and weekend day $(n=38)$. All participants were included in the analyses, except as indicated. 
Validity. Extensive methodological studies support the validity of this short-term recall method. In two studies, mothers of young children wrote what they were doing 30 to 40 times in a day when signaled by a beeper. Although they were not told they would be called the next day, the correlations between immediate recording and a recall diary on the subsequent day were .81 and .62 in two samples, respectively (Robinson, 1985). Recall by spouses for occasions when they were together agreed $81.2 \%$ of the time (Juster, 1985). Earlier studies also indicate that one 24-hr weekday diary is representative of other weekdays; time allocations tend to be similar, particularly for such frequent activities as child care (Juster, 1985).

Coding. The open-ended descriptions of activities were coded as: interactions with the study infant (which could occur in conjunction with caring for other children), paid work (including travel to and from work), school, housework, leisure, social, travel other than work, organizational, and caring for children other than the study infant when the infant was not present in the same room or not awake. The number of minutes spent in each category, as a primary or a secondary activity, was calculated for each 24-hr day.

The broad category, total infant time (all interactions with the study infant), was subdivided into instrumental care (feeding, bathing, diapering, and providing physical care) and social interaction (talking, holding, or other forms of interaction). Proportion of social interaction was the proportion of total infant time spent in social interaction.

Work was defined as paid work or attending school or both. By including both work and school time, we intended to capture the time women spent away from their infants engaged in an activity that increased the family's resources - by bringing in income, raising the mother's marketability, or providing a related benefit. At ages 6, 15, 24, and 36 months, respectively, the percentage of mothers in different employment statuses were: not working or in school, 32\%, 30\%, 29\%, 27\%; working only, $60 \%$, $61 \%, 62 \%, 63 \%$; in school only, $4 \%, 4 \%, 3 \%, 4 \%$; and both working and in school, $4 \%, 5 \%, 6 \%, 6 \%$. For the mothers who reported some work and school time, the average weekly hours in these activities reported at each age was: 6 months, $33.3(S D=14.0) ; 15$ months, $34.3(S D=14.3)$; 24 months, $34.3(S D=13.9)$; and 36 months, $34.1(S D=14.0)$. Work time from the 7-month diaries was highly, but not perfectly, correlated with the amount of time women reported spending at work $(r=.64, p<.001)$ during the 6month home interview.
Maternal employment status. On the basis of the work time reported in the time-use diaries, we separated the mothers into nonemployed (no work time) and employed (any work time) groups. Although it is possible that some employed women were classified inaccurately as nonemployed if they did not work on the interview days (e.g., because of vacation or illness), the interview schedule was designed to sample a workday if possible. Some women may have changed employment status before or after the 7-month diary sampling period, but, as one of the main questions in the study dealt with the possible impact of employment on time use, it seemed most reasonable to use the immediate measure of work time rather than a distal variable representing employment history.

\section{Quality of the Mother-Infant Relationship and the Home Environment}

Four dependent variables indicated the quality of the mother-child relationship and home environment: maternal sensitivity and child positive engagement during dyadic interactions, the HOME score, and the child's security of attachment.

Maternal sensitivity and child positive engagement. Both maternal sensitivity and child positive engagement were evaluated from semistructured videotaped 15-min dyadic interactions when the child was 6, 15, 24, and 36 months of age. At 6 months, the interaction included both free choice of activities and play with a standard set of toys. At 15, 24 , and 36 months, age-appropriate toys were provided in three boxes (details of the three-box procedure appear in NICHD Early Child Care Research Network, 1999). All sessions were videotaped and coded at a central location by coders who had no knowledge of the families' histories.

Maternal sensitivity at 6, 15, and 24 months was a composite of standardized scores from ratings on three 4-point scales: sensitivity to nondistress, intrusiveness (reverse scored), and positive regard. The maternal sensitivity composite at 36 months was the sum of supportive presence, hostility (reverse scored), and respect for autonomy ( $\alpha \mathrm{s}=.75, .70, .74$, and .78 for the 6-, 15-, 24-, and 36-month ratings, respectively). Intraclass correlations were used to assess coder agreement. For the maternal sensitivity composite, these correlations ranged from .83 to .87 for the four age levels. In the analyses presented here, the 15-, 24-, and 36-month scores are cumulative over time; each was the average of the composite score for that time of measurement and the composite scores of all previous times (e.g., the 
36-month score was the average of $6,15,24$, and 36 months). The means for each composite were 0 because they were standardized ( $S D \mathrm{~s}=.77$ to .85 ). Correlations across time ranged from .39 (from 6 months to 15 months) to .48 (from 24 months to 36 months).

A child positive engagement composite computed for 15- fand 24-month interactions was the average of standardized scores from two rating scales: positive mood and engagement with the mother $(r=.41$, $p<.01)$. At 36 months, it was the sum of child affection to mother and negativity (reverse scored). The means at each age were $0(S D s=1.00)$. Alphas were $.58, .74$, and .78 at 15,24 , and 36 months, respectively. Intraclass correlations representing coder agreement ranged from .70 to .77 . Child engagement scores were not averaged over time because their stability was relatively low ( $r \mathrm{~s}=.15$ to .27 ).

Home environment quality. The Infant/Toddler HOME (Caldwell \& Bradley, 1984) was administered at 6 and 15 months, and the Preschool HOME was administered at 36 months. The HOME is a semistructured interview and observational procedure designed to describe the stimulation and responsiveness of mothers, their involvement with and acceptance of their children, the availability of play and learning materials, and the organization and variety of the physical environment (Caldwell \& Bradley, 1984). Higher HOME scores indicate more enriched and positive home environments. All versions were converted to standard scores with a mean of 0 so that the two versions could be averaged ( $S D$ s of composites $=.87$ to .92 ). The 15- and 36-month scores were cumulative over time, such that each was the average of the score for that time of measurement and the previous times.

Security of attachment. Infant-mother attachment security was assessed at 15 and 36 months. At 15 months, the Ainsworth and Wittig Strange Situation procedure was used (Ainsworth, Blehar, Waters, \& Wall, 1978). Videotapes of all Strange Situation procedures were coded in a central location (different from the mother-child interaction coding site) by a team of three coders who were unaware of family status. These coders double-coded 1,201 Strange Situation assessments using the standard classifications of secure (B), insecure-avoidant (A), insecureresistant (C), disorganized (D), and unclassifiable (U). Disagreements were viewed by the group and a code was assigned by consensus. Across all coder pairs, before conferencing, agreement on the fivecategory coding system was $85 \%(\kappa=.69)$. A binary secure-insecure scoring is used in this report (for further information on attachment scoring, see NICHD Early Child Care Research Network, 1997a).
At 36 months, an age-appropriate version of the Strange Situation procedure was conducted. It involved a series of separations and reunions that were videotaped and coded according to the classification system developed by the MacArthur Working Group on Attachment (Cassidy, Marvin, and the MacArthur Working Group on Attachment, 1992). The coding system classifies preschoolers as secure (B) or insecure (A, C, or D; see NICHD Early Child Care Research Network, 2001, for details). All videotapes were coded at a single site using procedures similar to those for the 15-month coding. Before conferencing, agreement on the four-category ABCD classification was $75 \%(\kappa=.58)$. The proportions of children scored as secure were .62 and .61 at 15 and 36 months, respectively.

\section{Child Compliance, Social Competence, and Problem Behavior}

The measures used here were composites selected through factor analyses of observations and ratings of children's behavior in an earlier report of child social behavior (NICHD Early Child Care Research Network, 1998). Each composite is the average of measures loading on an independent factor; items whose factor loadings exceed .40 were included. All measures were converted to standard scores.

Clean-up compliance and defiance. During laboratory visits at 24 and 36 months, the mother was asked to have the child participate in picking up toys that had been used during the structured interaction. Videotapes of the ensuing interaction were coded on 5-point scales at a central location for compliance, assertive noncompliance, passive noncompliance, defiance, negative affect, and dyadic cooperation. Reliability of the ratings ranged from .81 to .93 using procedures outlined by Winer (1971). Two composites were formed for each age level: clean-up compliance (SDs $=3.40$ and 3.27 at 24 and 36 months) and clean-up defiance ( $S D s=1.85$ and 1.87 at 24 and 36 months).

Three-box negative. At 24 months, children's behavior during the mother-child dyadic interaction (the three-boxes procedure described earlier) was coded on 4-point scales for negative mood, activity level, and sustained attention $(S D=1.38)$. Winer (1971) estimates of interrater reliability ranged from .69 to .73 .

Three-box negative and resistance to temptation. At 36 months, the three-box interaction was coded for negative mood and task persistence. During the same laboratory session, the child was given the forbidden toy task. In this task, the child was given toys that he or she had already played with. An 
attractive new toy was placed at arm's length, and the child was told that he or she must wait to play with it while the adult did some paperwork. The measure of failure to resist temptation was the amount of time the child touched and played actively with the forbidden toy. Coding reliability was .98 for active play. The composite included negative mood, task persistence, and time playing with the forbidden toy $(S D=1.23)$.

Social competence. Mothers completed the Adaptive Social Behavior Inventory at 24 and 36 months. Two subscales loaded on one factor, Express, which taps sociability and empathy, and another factor, Comply, which measures prosocial engagement and cooperation. In addition, testers administering the Bayley Scale of Infant Development scored several items on whether the child complied with examiner requests. These were summed to form a score, compliance with the examiner. This score loaded highly on the factor with maternal ratings; therefore, it was included in the composite at 24 months $(S D=1.78)$. There was no comparable test at 36 months $(S D=1.72)$.

Behavior problems. Mothers completed the Child Behavior Checklist at 24 and 36 months. Two broad band scales, Internalizing and Externalizing, and two narrow-band scales, Somatic and Sleep Problems, all loaded on a single factor. One subscale from the Adaptive Social Behavior Inventory, Disrupt, assessing resistant and agonistic behavior, also loaded on this factor and was included in the composite $(S D s=3.72$ and 3.73 at 24 and 36 months, respectively). Details of all measures and procedures for compositing appear in NICHD Early Child Care Research Network (1998).

\section{Cognitive and Language Development}

At 24 months, the Mental Development Index (MDI) from the Bayley II (Bayley, 1993) was used to assess overall developmental status $(M=92.15$, $S D=14.64)$. At 36 months, the Expressive Language and Vocabulary Comprehension scales of the Reynell Developmental Language Scales were administered (Reynell, 1991). All three measures are based on agestandardized scores with a mean of $100(S D=15)$. In this sample, $M=96.88, S D=14.53$ for expressive language, and $M=97.85, S D=15.85$ for vocabulary comprehension.

\section{Maternal and Family Characteristics}

Maternal and family characteristics were assessed when the infant was 1 and 6 months old. Except for unchanging characteristics (e.g., birth order), the 6- month values were used in the analyses. They included maternal age $(M=28.11, S D=5.63)$, ethnicity (.80 were non-Hispanic White), education (years of schooling, $M=14.23, S D=2.51$ ), family income-toneeds ratio (total family income divided by the poverty threshold based on family size, $M=3.66$, $S D=3.10$ ), child gender (.52 male), birth order (because children were 7 months old, this is exactly equal to number of children in the family, $M=1.83$, $S D=.95$ ), and marital/partner status (married vs. cohabiting vs. single, $M=1.36, S D=.71$ ).

Maternal psychological adjustment was a composite score created by summing the average scores on two mental health scales: the Center for Epidemiological Studies Depression Scale (CES-D, Radloff, 1977; reverse scored), and three scales from the NEO Personality Inventory (Costa \& McCrae, 1985) - neuroticism (reverse scored), extraversion, and agreeableness $(\alpha=.80)$. Higher scores indicate greater psychological adjustment. Scores were standardized $(M=0, S D=2.93)$.

Mother's attitudes and beliefs related to maternal employment and the maternal role were measured when the infant was 1 month old with the Attitude Toward Maternal Employment Questionnaire (Greenberger, Goldberg, Crawford, \& Granger, 1988). The score was composed of five 6-point items designed to measure beliefs that maternal employment is beneficial to children $(\alpha=.80)$ and six items designed to measure beliefs that maternal employment is harmful to children (reverse scored; $\alpha=.88$ ). Higher scores indicate a stronger belief that work is beneficial for children $(M=.85, S D=7.12)$.

Separation anxiety was measured using the Parental Care Questionnaire (DeMeis, Hock, \& McBride, 1986). The 21 items assess maternal feelings of concern, sadness, and guilt when separated from her infant, and her beliefs about maternal and nonmaternal care $(\alpha=.93)$. Higher scores indicate more separation anxiety $(M=66.42, S D=13.84)$.

Progressive attitudes about childrearing was measured using the Modernity Scale (Schaefer \& Edgerton, 1985). The score was the sum of eight 5-point items designed to measure traditional authoritarian and progressive democratic beliefs about parenting $(\alpha=.60)$. Higher scores indicate more progressive attitudes $(M=32.73, S D=3.52)$.

\section{Results}

\section{Employment and Time Use}

How does employment relate to mothers' time with their infants? Employed and nonemployed 
Table 1

Number of Minutes in Activities for Employed and Nonemployed Mothers Over 2 Days

\begin{tabular}{|c|c|c|c|c|c|}
\hline & \multicolumn{2}{|c|}{$\begin{array}{c}\text { Nonemployed } \\
\quad(n=363)\end{array}$} & \multicolumn{2}{|c|}{$\begin{array}{l}\text { Employed } \\
(n=690)\end{array}$} & \multirow[b]{2}{*}{$F(1,1052)$} \\
\hline & $M$ & $S D$ & $M$ & $S D$ & \\
\hline Paid work/school & 0 & & 509.13 & 203.25 & $2276.04^{* * *}$ \\
\hline Household & 398.18 & 171.69 & 295.20 & 156.36 & $90.71^{* * *}$ \\
\hline Leisure & 521.42 & 260.21 & 360.62 & 181.90 & $142.24^{* * *}$ \\
\hline Organization & 48.86 & 90.39 & 32.36 & 71.07 & $9.75^{* *}$ \\
\hline Social & 232.12 & 169.00 & 171.47 & 143.94 & $39.27^{* * *}$ \\
\hline Travel & 81.54 & 75.51 & 75.53 & 65.42 & 1.66 \\
\hline Total infant time & 635.32 & 244.07 & 531.97 & 184.78 & $65.26^{* * *}$ \\
\hline Instrumental care & 360.25 & 162.95 & 287.93 & 124.14 & $71.38^{* * *}$ \\
\hline Social interaction & 275.07 & 175.02 & 244.04 & 141.12 & $12.86^{* * *}$ \\
\hline Proportion social & .41 & .19 & .44 & .18 & $4.75^{*}$ \\
\hline
\end{tabular}

Note. $F$ ratios indicate tests of mean differences with site covaried. Because certain categories of time are not included in the table and some time appears in more than one category, the minutes do not add up to $24 \mathrm{hr}$.

${ }^{*} p<.05 .{ }^{* *} p<.01 .{ }^{* * *} p<.001$.

mothers' allocations of time to the major activity categories appear in Table 1. Results of a multivariate analysis of covariance (MANCOVA) controlling for site demonstrated that employed and nonemployed mothers' time use differed, overall $F(7,1036)=$ $327.88, p<.001$, and univariate contrasts indicated that they allocated different amounts of time to each activity except travel. It is not surprising that employed women spent less time in all activities other than paid work than did mothers who were not employed, but employment was associated with proportionally greater reductions in household, leisure, organizational, and social activity than in infant care. Employed mothers spent from $66 \%$ to $74 \%$ as much time as nonemployed mothers in the four nonchild care activities; they spent $84 \%$ as much time as nonemployed mothers caring for the study child. As a result, despite spending an average of about $500 \mathrm{~min}$ (or the equivalent of one 8-hr day) at work over the 2 days, employed mothers only spent about $100 \mathrm{~min}$ (about $1.7 \mathrm{hrs}$ ) less with their infants than did nonemployed women. Employed mothers spent a greater percentage of their available time (time available after subtracting work time) with their infant than did nonemployed women (58\% vs. $44 \%$, respectively), $F(1,1052)=77.05, p<.001$.

Types of time with infant. Employed women spent their time with their infants differently than did nonemployed women, MANCOVA overall $F(3$, $1040)=30.31, p<.001$. Employed women spent significantly less time engaged in both instrumental care and social interaction, but they spent a slightly higher proportion of their time engaged in social interaction than did nonemployed women (see Table 1).

Weekday versus nonweekday. We compared employed and nonemployed mothers' infant time on the weekday and weekend day. Only the 513 mothers who worked on a weekday and not on the weekend were included in this analysis. Compared with nonemployed mothers, employed mothers spent significantly less time with their infant on the weekday but significantly more time with their infant on the weekend day (see Table 2). The difference

Table 2

Infant Time by Maternal Employment Status and Day of Week

\begin{tabular}{|c|c|c|c|c|c|c|}
\hline & \multicolumn{2}{|c|}{ Weekday } & \multirow[b]{3}{*}{$F(1,882)$} & \multicolumn{2}{|c|}{ Weekend } & \multirow[b]{3}{*}{$F(1,882)$} \\
\hline & $\begin{array}{c}\text { Nonemployed } \\
n=363\end{array}$ & $\begin{array}{c}\text { Employed } \\
n=520\end{array}$ & & $\begin{array}{c}\text { Nonemployed } \\
n=363\end{array}$ & $\begin{array}{c}\text { Employed } \\
n=520\end{array}$ & \\
\hline & $M(S D)$ & $M(S D)$ & & $M(S D)$ & $M(S D)$ & \\
\hline Total infant time & $\begin{array}{c}332.58 \\
(148.04)\end{array}$ & $\begin{array}{c}203.32 \\
(103.47)\end{array}$ & $241.65^{* * *}$ & $\begin{array}{c}302.74 \\
(135.99)\end{array}$ & $\begin{array}{c}332.50 \\
(128.80)\end{array}$ & $12.89^{* * *}$ \\
\hline Instrumental care & $\begin{array}{l}186.45 \\
(92.39)\end{array}$ & $\begin{array}{l}113.44 \\
(65.58)\end{array}$ & $192.49^{* * *}$ & $\begin{array}{l}173.80 \\
(95.30)\end{array}$ & $\begin{array}{l}174.88 \\
(86.76)\end{array}$ & 0.82 \\
\hline Social interaction & $\begin{array}{c}146.13 \\
(110.30)\end{array}$ & $\begin{array}{c}89.88 \\
(71.57)\end{array}$ & $91.40^{* * *}$ & $\begin{array}{l}128.94 \\
(99.81)\end{array}$ & $\begin{array}{c}157.63 \\
(107.76)\end{array}$ & $14.08^{* * *}$ \\
\hline Proportion scial & $\begin{array}{c}0.40 \\
(0.22)\end{array}$ & $\begin{array}{c}0.42 \\
(0.23)\end{array}$ & 0.44 & $\begin{array}{c}0.39 \\
(0.24)\end{array}$ & $\begin{array}{c}0.45 \\
(0.22)\end{array}$ & $9.09^{* *}$ \\
\hline
\end{tabular}

Note. F ratios indicate tests of mean differences with site controlled. The employed mothers group includes only mothers who worked on a weekday and not on a weekend day. Excluded were 55 employed mothers who worked on the weekend day and not the weekday and 115 employed mothers who worked both days. ${ }^{* *} p<.01 .{ }^{* * *} p<.001$. 
in weekend time was accounted for entirely by more social interaction; there was no difference in instrumental care.

\section{Maternal Characteristics Associated With Time Use and Maternal Behavior}

We next examined the relationship of both time use and maternal behavior to a large number of family and maternal characteristics: age, education, ethnic group, psychological adjustment, child's gender and birth order, family income, family structure, maternal belief in the benefits of maternal employment, separation anxiety, and progressive childrearing beliefs. Zero-order correlations of all these covariates with time use are shown in Table 3, and correlations of these covariates with maternal sensitivity and HOME scores are shown in Table 4. We regressed three time-use variables on the set of covariates to determine which maternal and demographic characteristics were associated with infant time, work time, and available time with infant (work time included as a control). The results appear in Table 5.

Table 3

Correlations of Time Spent With Infant With Covariates, Mother-Infant Relationship, and Child Developmental Outcomes

\begin{tabular}{|c|c|c|c|c|c|}
\hline \multirow[b]{2}{*}{ Variable } & \multicolumn{5}{|c|}{ Type of time } \\
\hline & Work & Total infant & Instrumental & Social interaction & Proportion social \\
\hline Age of mother & .05 & $.13^{* * *}$ & $.17^{* * *}$ & .01 & -.05 \\
\hline Education & $.14^{* * *}$ & $.08^{*}$ & $.06^{*}$ & .05 & .05 \\
\hline White non-Hispanic & .02 & $.12^{* * *}$ & $.07^{*}$ & $.10^{* *}$ & .05 \\
\hline Adjustment & $.11^{* * *}$ & .05 & .00 & $.07^{*}$ & $.09^{*}$ \\
\hline Male child & .00 & -.04 & -.03 & -.03 & .00 \\
\hline Birth order & $-.22 * * *$ & $-.12^{* * *}$ & .03 & $-.19^{* * *}$ & $-.20 * * *$ \\
\hline Income to needs & $.20 * * *$ & .00 & .01 & .01 & .04 \\
\hline Partner group & -.02 & -.05 & $-.07^{*}$ & .00 & .01 \\
\hline Benefits employment & $.31^{* * *}$ & $-.14^{* * *}$ & $-.09^{* *}$ & $-.11^{* * *}$ & -.04 \\
\hline Separation anxiety & $-.19^{* * *}$ & $.12^{* * *}$ & $.10^{* *}$ & $.07^{*}$ & -.03 \\
\hline Progressive childrearing & .05 & $.06^{*}$ & $.09^{* *}$ & .00 & -.03 \\
\hline Maternal sensitivity 6 & .04 & $.08^{* *}$ & $.08^{* *}$ & .04 & .01 \\
\hline Maternal sensitivity 15 & .05 & $.12^{* * *}$ & $.10^{* *}$ & $.07^{*}$ & .02 \\
\hline Maternal sensitivity 24 & $.09^{* *}$ & $.12^{* * *}$ & $.09^{* *}$ & $.08^{*}$ & .04 \\
\hline Maternal sensitivity 36 & $.08^{*}$ & $.14^{* * *}$ & $.11^{* * *}$ & $.10^{* *}$ & .05 \\
\hline HOME 6 & .06 & $.24^{* * *}$ & $.19^{* * *}$ & $.15^{* * *}$ & $.07^{*}$ \\
\hline HOME 15 & $.09^{* *}$ & $.27^{* * *}$ & $.24^{* * *}$ & $.15^{* * *}$ & .05 \\
\hline HOME 36 & $.10^{* *}$ & $.27^{* *}$ & $.21^{* * *}$ & $.17^{* * *}$ & $.08^{*}$ \\
\hline Child engagement 15 & .05 & -.04 & .00 & -.05 & -.04 \\
\hline Child engagement 24 & -.01 & -.04 & -.06 & .00 & .05 \\
\hline Child engagement 36 & -.02 & .02 & .06 & -.03 & -.04 \\
\hline Secure attachment 15 & -.02 & .01 & .04 & -.03 & -.04 \\
\hline Secure attachment 36 & .02 & .01 & -.02 & .03 & .04 \\
\hline Compliance 24 & .03 & -.04 & -.02 & -.03 & -.04 \\
\hline Compliance 36 & .02 & -.04 & -.03 & -.02 & -.01 \\
\hline Defiance 24 & .00 & -.02 & -.02 & -.01 & .01 \\
\hline Defiance 36 & .03 & .04 & $.07^{*}$ & -.01 & -.03 \\
\hline Three-box negative 24 & .01 & -.01 & .01 & -.02 & -.03 \\
\hline Three-box negative 36 & .00 & .05 & -.00 & $.07^{*}$ & .05 \\
\hline Social competence 24 & $.08^{*}$ & .06 & .02 & .06 & .04 \\
\hline Social competence 36 & .05 & .06 & .03 & .05 & .04 \\
\hline Behavior problems 24 & -.07 & -.00 & .01 & -.01 & -.01 \\
\hline Behavior problems 36 & -.02 & .01 & -.00 & .01 & -.00 \\
\hline Bayley MDI 24 & $.10^{* *}$ & .04 & -.02 & $.07^{*}$ & .06 \\
\hline Expressive language 36 & $.09^{*}$ & -.03 & $-.08^{*}$ & .03 & $.08^{*}$ \\
\hline Vocabulary 36 & $.08^{*}$ & $.10^{* *}$ & .04 & $.10^{* *}$ & $.07^{*}$ \\
\hline
\end{tabular}

Note. $\mathrm{HOME}=$ Home Observation for Measurement of the Environment; MDI = Mental Development Index. ${ }^{*} p<.05 .{ }^{* *} p<.01 .{ }^{* * *} p<.001$. 
Maternal and demographic characteristics accounted for $18 \%$ of the variability in infant time, $27 \%$ of the variability in available time with the infant, and $20 \%$ of the variability in work time. Although the magnitudes of the relations were modest, different groups of predictors were associated with infant time and work time. Mothers who spent more time with their children were older, White, had better psychological adjustment, had fewer children, had lower incomes, had high separation anxiety, and believed that maternal employment was not good for children. Several of the same characteristics predicted the amount of available time (i.e., time outside work hours) mothers spent with their children, except that income and beliefs about maternal employment dropped out. Mothers who spent more time at work also had fewer children, but they had higher incomes, low separation anxiety, and positive beliefs about the benefits of maternal employment.

Maternal and demographic characteristics accounted for $39 \%$ and $53 \%$ of the variability in maternal sensitivity and HOME scores, respectively. Both scores were higher for mothers who were older, more educated, White, better adjusted, and married, and had progressive attitudes about childrearing, did not believe in the benefits of maternal employment, and had female children. Less sensitive mothers had high separation anxiety, and those with more children had lower HOME scores. Family income was the only predictor that was not related to either sensitivity or HOME scores.

Time With the Infant and the Mother-Infant Relationship

Zero-order correlations of time use with the dependent variables are shown in Table 3. To assess the relations of time with the infant and time at work to the mother-child relationship, we fitted models regressing the dependent variables on time with infant and work time, controlling for the set of family and maternal characteristics.

Maternal sensitivity and HOME scores. We show the results for the cumulative average from 6 to 36 months in Table 6. Mother's total time with the infant predicted average maternal sensitivity and average HOME scores over the child's first 3 years of life. Even with extensive statistical controls for demographic and other characteristics, those who spent more time with their infants demonstrated greater sensitivity and had higher HOME scores. Time in instrumental care was not significantly related to maternal sensitivity but was positively associated 
Table 5

Standardized Regression Coefficients for Three Types of Time Use Regressed on Maternal and Family Characteristics

\begin{tabular}{|c|c|c|c|c|c|}
\hline & $\begin{array}{c}\text { Total time } \\
\text { with infant }\end{array}$ & $\begin{array}{l}\text { Available time } \\
\text { with infant (work } \\
\text { time controlled) }\end{array}$ & Work time & $\begin{array}{c}\text { Maternal } \\
\text { sensitivity } 36\end{array}$ & $\begin{array}{c}\text { HOME } \\
\text { scale } 36\end{array}$ \\
\hline Age & $.22 * * *$ & $.22^{* * *}$ & .01 & $.06^{\dagger}$ & $.17^{* * *}$ \\
\hline Education & .00 & .01 & .03 & $.28^{* * *}$ & $.20^{* * *}$ \\
\hline White & $.08^{* *}$ & $.07^{*}$ & -.04 & $.17^{* * *}$ & $.13^{* * *}$ \\
\hline Adjustment & $.08^{*}$ & $.09^{* *}$ & .04 & $.13^{* * *}$ & $.15^{* * *}$ \\
\hline Male child & -.03 & -.03 & .01 & $-.11^{* * *}$ & $-.05^{*}$ \\
\hline Birth order & $-.17^{* * *}$ & $-.23^{* * *}$ & $-.17^{* * *}$ & .02 & $-.16^{* * *}$ \\
\hline Income to needs & $-.10^{* *}$ & -.06 & $.09^{*}$ & .05 & .04 \\
\hline Cohabiting & .01 & .02 & .04 & $-.08^{* *}$ & $-.13^{* * *}$ \\
\hline Single & .03 & .03 & -.01 & $-.08^{* *}$ & $-.24^{* * *}$ \\
\hline Benefits of maternal employment & $-.14^{* * *}$ & -.03 & $.32^{* * *}$ & $-.05^{*}$ & $-.10^{* * *}$ \\
\hline Separation anxiety & $.18^{* * *}$ & $.15^{* * *}$ & $-.08^{*}$ & $-.06^{*}$ & -.002 \\
\hline Progressive childrearing & .03 & .04 & .006 & $.11^{* * *}$ & $.13^{* * *}$ \\
\hline Adjusted $R^{2}$ & $.18^{* * *}$ & $.27^{* * *}$ & $.20 * * *$ & $.39 * * *$ & $.53^{* * *}$ \\
\hline
\end{tabular}

Note. $N=1,026$. Site was included as a control. HOME $=$ Home Observation for Measurement of the Environment. ${ }^{\dagger} p=.05 .{ }^{*} p<.05 .{ }^{* *} p<.01 .{ }^{* * *} p<.001$.

with HOME scores. Time in social interaction predicted both sensitivity and HOME.

Work time was included in these analyses. With controls for the covariates and for time with the infant, mothers who spent more time at work provided higher quality home environments (as measured by the HOME total score). Work time did not significantly predict maternal sensitivity.

Although outside work reduces the time available for other activities, mothers have discretion about using their nonwork time. The analyses that include work time enable us to determine whether the amount of available (i.e., nonwork) time with the infant was associated with the dependent variables. We repeated all analyses without work time in the model, and the results for infant time were similar (not shown), suggesting that infant time and work time have independent effects.

Child engagement and attachment. Hierarchical regressions of child engagement at each period indicated few relations between maternal time with the infant and child engagement. Of nine analyses, three produced significant negative relations, contrary to the predicted direction. Time spent in social interaction predicted less positive infant engagement at 15 months $(\beta=-.07, p<.05)$, and both total time

Table 6

Standardized Regression Coefficients for Average Maternal Sensitivity and HOME Over 3 Years Regressed on Three Types of Time

\begin{tabular}{|c|c|c|c|c|c|c|}
\hline \multirow[b]{3}{*}{ Variable } & \multicolumn{3}{|c|}{ Maternal sensitivity 36} & \multicolumn{3}{|c|}{ HOME 36} \\
\hline & \multicolumn{6}{|c|}{ Type of time } \\
\hline & Total & Instrumental & Social & Total & Instrumental & Social \\
\hline Adjusted $R^{2}$ for covariates & $.39^{* * *}$ & $.39 * * *$ & $.39 * * *$ & $.53^{* * *}$ & $.53^{* * *}$ & $.53^{* * *}$ \\
\hline Work time & .04 & .03 & .03 & $.06^{*}$ & .05 & .03 \\
\hline Infant time & $.07^{* *}$ & .03 & $.06^{*}$ & $.14^{* * *}$ & $.11^{* * *}$ & $.08^{* * *}$ \\
\hline$\Delta R^{2}$ for infant time & $.00^{* *}$ & .001 & $.00^{*}$ & $.01 * * *$ & $.01 * * *$ & $.01^{* * *}$ \\
\hline Adjusted $R^{2}$ & $.40^{* * *}$ & $.39 * * *$ & $.40^{* * *}$ & $.54^{* * *}$ & $.54^{* * *}$ & $.54^{* * *}$ \\
\hline
\end{tabular}

Note. $N=1,026$. Site was included as a control. The coefficients for the covariates are presented for total time in Table 5 . The relations of the covariates to instrumental care and social interaction time are similar to those for total time. HOME $=$ Home Observation for Measurement of the Environment.

${ }^{*} p<.05 .{ }^{* *} p<.01 .{ }^{* * *} p<.001$. 
with the infant $(\beta=-.08, p<.05)$ and time spent in instrumental care $(\beta=-.11, p<.01)$ were negatively related to engagement at 24 months. Logistic regressions including the covariates were used to predict secure attachment at 15 and 36 months. There were no significant relations of maternal time to attachment security.

\section{Maternal Time and Children's Development}

Compliance and social competence. Relations between maternal time and children's compliance and social competence were tested in 30 analyses (five behaviors at each of two ages by three types of maternal time). There was one significant association with maternal time, which is best interpreted as a chance finding. Overall, maternal time with the in fant was unrelated to children's social competence.

Cognitive and language development. Maternal time with the infant was not related to Bayley MDI at 24 months or to vocabulary comprehension at 36 months. However, mothers who had spent more time with their infants had children who performed less well on expressive language $(\beta=-.09, p<.05)$; this association appeared to be a function of time in instrumental care $(\beta=-.10, p<.01)$.

\section{Discussion}

In this study we sought to understand how mothers' time with their infants is related to the mother-child relationship, the quality of the home environment, and children's early social and cognitive development. Time-use research has provided information about the amount of time mothers spend caring for their children, but these studies have primarily included mothers of older children (e.g., Bryant \& Zick, 1996a; Gershuny \& Robinson, 1988; Robinson \& Godbey, 1997). The current research extended these findings to mothers of infants.

Both economic and developmental theories identify the time a mother spends caring for her infant as an important contributor to social and intellectual development. Economic theories of the family define parent-child time as a social capital resource, providing opportunities for stimulation and social interaction. Attachment theory and social learning theories predict that time for interaction with the infant is crucial for developing strong mother-infant bonds that lead to secure attachment and for providing cognitive and social stimulation. All of these theories imply that time should predict child social and cognitive development if that time is devoted to interactions with the child.
Our findings provide support for the prediction that mothers who spend more time with their infants, particularly time devoted to social interaction, are more sensitive and provide higher quality home environments during the child's early years. All three measures of maternal time with the infant predicted HOME scores, and both total time with the infant and time engaged in social interaction predicted maternal sensitivity. The zeroorder correlations were modest, however, and once an extensive array of individual and family characteristics was controlled, time with the infant added little to the prediction of sensitivity or to HOME scores.

Despite the modest association between mothers' time with their infants and outcomes measuring the mother's side of the relationship-maternal sensitivity and the quality of the home environment - there is no evidence in our findings that time with the infant increases the infant's engagement with his or her mother or contributes to the child's social or cognitive development. There were few significant relations between time and children's behavior, and the few significant associations ran contrary to prediction. Children's engagement with their mothers, compliance to requests in observed social interaction, and expressive language were slightly lower when mothers had spent more time with them in infancy. These findings are consistent with those reported by Booth et al. (2002) for toddlers who were 15 months old. Despite the association of maternal time with maternal behavior, it does not appear to be a determinant of children's social or cognitive development in the early years.

One reason that maternal time may fail to predict children's development is that we have insufficient information about the content and quality of the interactions between mother and child. Both economic and developmental theories predict that time is necessary but not sufficient. The time must be spent in attentive and sensitive interactions to influence development. Although we attempted to measure quality time by separating instrumental and social interaction time, this indicator may have failed to capture the important content of the interactions. It is also possible that, above some minimum threshold, there are diminishing returns associated with time, or that the amount of time is simply less important than the types of interaction that take place when mothers are with their infants. Finally, we have no information about the infants' time with fathers or other important caregivers that could have contributed to their social and intellectual development. 
Maternal Employment, Infant Time, and Children's Development

Employed mothers of infants spent less time on average with their infants than did nonemployed mothers, but the difference was much smaller than would be expected based on the amount of time that mothers spent at work. Over 2 days, employed women worked an average of about $8 \mathrm{hr}$ but spent only 1.7 fewer hours with their infants than did nonemployed women. Because we selected a weekday and a weekend day, these data may underestimate the time differences on a weekly basis. When children were 6 months old, the average employed mother worked about $33 \mathrm{hr}$ a week, or the equivalent of approximately four full-time days. It might be reasonable to assume, therefore, that our weekday represents infant time on about 4 of the most 7 typical days, and our weekend day represents about 3 , with the caveat that there was wide individual variation in both employment hours and schedules.

The current findings go beyond those previously reported by Booth et al. (2002) by providing detail regarding the choices employed mothers make to spend time with their infants. First, employed women, compared with nonemployed women, reduced time proportionally more in housework, leisure, organizational, and social activities, and they spent a higher percentage of their available time (i.e., nonwork time) with their infants. The larger differences in household and leisure time suggest that employed women sacrificed household tasks and leisure activities to spend time with their children.

Second, employed women compensated for lost time during the week by increasing time with their infant on the weekend. In contrast, nonemployed women reduced time with their infant on the weekend. As a result, employed women spent more time with their infants on the weekend day than did nonemployed women. In fact, on average, employed women spent as much time with their infants on the weekend day as nonemployed women spent with their babies on the weekday. Finally, compared with nonemployed women, employed women devoted a slightly higher proportion of their time with their infant to purely social activities, such as playing, talking, or holding their infants, and a lower proportion to instrumental care.

There was no evidence that mothers' time at work interfered with the quality of their relationships with their infants, the quality of the home environment, or children's development. In fact, the results suggest the opposite. Mothers who spent more time at work provided slightly higher quality home environments than did those who spent less time at work (even with controls for numerous personality and demographic variables that are associated with maternal employment), and there were no significant associations of work time with maternal sensitivity or children's development.

In short, both time with infants and time at work were associated with higher quality home environments, suggesting that any effect of maternal employment in infancy is probably not a consequence of the reduced time with the infant that results from employment. The economic and social benefits of maternal employment outweigh any losses that may result from the time spent away from the child, fathers and other caregivers may spend more time with children when mothers are employed, or unmeasured characteristics of mothers may affect time allocation to both employment and parenting.

\section{Time With Infants as a Result Rather Than a Cause}

The most parsimonious interpretation of our findings seems to be that the amount of time mothers spend with their infants is a sign of maternal investment more than a cause of their parenting. First, although mother-infant time modestly predicts maternal behavior, it does not contribute to the child's side of the relationship with the mother or to child social and cognitive outcomes. Second, most of the variance in maternal sensitivity and home scores is accounted for by maternal and family characteristics. Third, available time rather than absolute amount of time is the relevant contributor to the outcomes that are predicted by time with the infant - the HOME scores and maternal sensitivity. A mother's choices about how to allocate her time may result from individual differences among mothers and families, differences that also contribute to mothers' ability to respond sensitively to their infants and to create stimulating home environments. Rather than being a cause of maternal sensitivity and stimulating homes, choices about time use may reflect individual characteristics that influence both time use and type of mothering.

This interpretation is consistent with our findings that certain personal and family characteristics predict both use of available time and type of mothering. Women who had fewer children spent more available time with their children and provided higher quality home environments for their infants, despite the fact that they also spent more time at work. Women who were older, White, and better adjusted psychologically spent more time with their 
infants, were more sensitive mothers, and provided more stimulating home environments, but these three factors were not related to the time spent working. It is interesting that although women with higher incomes spent more time at work and less total time with their infants than did lower income women, these women did not differ in the amount of available time they spent with their children, nor did they differ in maternal sensitivity or quality of their home environments. Women who were most concerned about separation from their infants spent more time with their infants and less time at work, but they were less sensitive than those with less separation anxiety. By contrast, women who believed that maternal employment was beneficial to children spent less time with their children and more time at work, and they were less sensitive and provided lower quality home environments than did women who believed work was less beneficial to children.

In other words, women who spent more time with their infants and those who spent more time at work were similar in that they had fewer children, but they had different attitudes and beliefs about the effects of maternal employment and separation on their infants' well-being. These differences appear to be specific to issues of mother-child separation; these groups of mothers did not differ on more general progressive or traditional beliefs about childrearing.

\section{Conclusions}

Whether or not they are employed, the amount of available time mothers spend with their infants is an indicator of positive mothering and the quality of the child's home environment. Individual characteristics of mothers and families contribute both to choices about how to spend time and to the quality of mothering and the home environment. Our findings suggest that time - either time spent at work or time spent with infants - may play a less important causal role in developing sensitive mothers and creating high-quality home environments than both economic and developmental theories predict. Rather, mothers whose family situations and personal dispositions lead them to be more sensitive and to provide stimulating and warm home environments may choose or be able to spend more of their available time with their infants, whether or not they are employed.

We also found that mothers who spent more time at work provided slightly higher quality home environments, even though they did not have more education or better psychological adjustment. Employment may contribute some positive benefits to the family environment because of the income it generates or the intellectual and social stimulation it provides for the mother (Parcel \& Menaghan, 1994). Even though this study contains a large and diverse group of mothers, it cannot be interpreted as demonstrating effects of maternal employment in contexts where mothers have little choice. Mothers in this study made their own decisions about employment, and those decisions, on average, were consistent with individual attitudes and beliefs about the effects of employment and separation on their infants (Chang, 2003). Within the constraints of economic necessity and job availability, women probably select the combination of employment and childrearing that fits their values, and their satisfaction with the balance of work and family may facilitate a positive relationship with their infant.

\section{References}

Ahnert, L., Rickert, H., \& Lamb, M. (2000). Shared caregiving: Comparisons between home and child-care settings. Developmental Psychology, 36, 339-351.

Ainsworth, M. D., Blehar, M., Waters, E., \& Wall, S. (1978). Patterns of attachment: A psychological study of the Strange Situation. Hillsdale, NJ: Erlbaum.

Almeida, D. (1997, November). National study of daily experiences: Examining quantity and quality of child-related experiences through daily telephone diaries. Paper presented at the Conference on Time-Use, Non-Market Work, and Family Well-being. Washington, D.C.

Bayley, N. (1993). Bayley Scales of Infant Development (2nd ed.) San Antonio, TX: Psychological Corporation.

Becker, G. S. (1981). A treatise on the family. Cambridge, MA: Harvard University Press.

Belsky, J. (2001). Developmental risk (still) associated with early child care. Journal of Child Psychology and Psychiatry, $42,845-860$.

Belsky, J., \& Eggebeen, D. (1991). Early and extensive maternal employment and young children's socioemotional development: Children of the National Longitudinal Survey of Youth. Journal of Marriage and the Family, 53, 1083-1098.

Bianchi, S. M. (2000). Maternal employment and time with children: Dramatic change or surprising continuity? Demography, 37, 401-414.

Booth, C. L., Clarke-Stewart, K. A., Vandell, D. L., McCartney, K., \& Owen, M. T. (2002). Child-care usage and mother-infant "quality time". Journal of Marriage and Family, 64, 16-26.

Brazelton, T. B. (1986). Issues for working parents. American Journal of Orthopsychiatry, 56, 14-25.

Brooks-Gunn, J., Han, W., \& Waldfogel, J. (2002). Maternal employment and the child cognitive outcomes in the first three years of life: The NICHD Study of Early Child Care. Child Development, 73, 1052-1072. 
Broom, B. L. (1998). Parental sensitivity to infants and toddlers in dual-earner and single-earner families. Nursing Research, 47, 162-170.

Bryant, W. K., \& Zick, C. D. (1996a). An examination of parent-child shared time. Journal of Marriage and the Family, 58, 227-237.

Bryant, W. K., \& Zick, C. D. (1996b). Are we investing less in the next generation? Historical trends in time spent caring for children. Journal of Family and Economic Issues, 17, 365-392.

Caldwell, B. M., \& Bradley, R. H. (1984). The HOME inventory and family demographics. Developmental Psychology, 20, 315-320.

Cassidy, J., Marvin, R. S. \& the MacArthur Working Group on Attachment. (1992). Attachment organization in preschool children: Procedures and coding manual. Unpublished coding manual, Pennsylvania State University.

Chang, Y. E. (2003). Mothers' attitudes toward employment, maternal well-being, maternal sensitivity and children's socioemotional outcomes when mothers engage in different amounts of employment. Unpublished doctoral dissertation, University of Texas at Austin.

Chase-Lansdale, P. L., \& Owen, M. T. (1987). Maternal employment in a family context: Effects on infantmother and infant-father attachments. Child Development, 58, 1505-1512.

Clark, R., Hyde, J. S., Essex, M. J., \& Klein, M. H. (1997). Length of maternity leave and quality of mother-infant interactions. Child Development, 68, 364-383.

Coleman, J. S. (1988). Social capital in the creation of human capital. American Journal of Sociology, 94, S95-S120.

Costa, P. T., \& McCrae, R. R. (1985). The NEO Personality Inventory manual. Odessa, FL: Psychological Assessment Resources.

Cox, M. J., Owen, M. T., Henderson, V. K., \& Margand, N. A. (1992). Prediction of infant-father and infantmother attachment. Developmental Psychology, 28, $474-483$.

Crockenberg, S., \& Litman, C. (1991). Effects of maternal employment on maternal and two-year-old child behavior. Child Development, 62, 930-953.

DeMeis, D. K., Hock, E., \& McBride, S. L. (1986). The balance of employment and motherhood: Longitudinal study of mothers' feelings about separation from their first-born infants. Developmental Psychology, 22, $627-632$.

Desai, S., Chase-Lansdale, P., \& Michael, R. T. (1989). Mother or market? Effects of maternal employment on the intellectual ability of 4-year-old children. Demography, 26, 545-561.

Easterbrooks, M. A., \& Goldberg, W. A. (1985). Effects of early maternal employment on toddlers, mothers and fathers. Developmental Psychology, 21, 774-783.

Feldman, R., Sussman, A. L., \& Zigler, E. (2004). Parental leave and work adaptation at the transition to parenthood: Individual, marital, and social correlates. Journal of Applied Developmental Psychology, 25, 459-480.
Gershuny, J., \& Robinson, J. P. (1988). Historical changes in the household division of labor. Demography, 25, $537-552$.

Gottfried, A. E., Gottfried, A. W., \& Bathurst, K. (1988). Maternal employment, family environment, and children's development: Infancy through the school years. In A. E. Gottfried \& A. W. Gottfried (Eds.), Maternal employment and children's development: Longitudinal research (pp. 11-58). New York: Plenum.

Gottfried, A. E., Gottfried, A. W., Bathurst, K., \& Killian, C. (1999). Maternal and dual-earner employment: Family environment, adaptations, and the developmental impingement perspective. In M. E. Lamb (Ed.), Parenting and child development in "nontraditional" families (pp. 1537). Mahwah, NJ: Erlbaum.

Greenberger, E., Goldberg, W., Crawford, T. J., \& Granger, J. (1988). Beliefs about the benefits of maternal employment for children. Psychology of Women Quarterly, 12, 35-59.

Greenstein, T. N. (1995). Are the "most advantaged" children truly disadvantaged by early maternal employment? Effects on child cognitive outcomes. Journal of Family Issues, 16, 149-169.

Han, W., Waldfogel, J., \& Brooks-Gunn (2001). The effects of early maternal employment on later cognitive and behavioral outcomes. Journal of Marriage and the Family, 63, 336-354.

Harvey, E. (1999). Short-term and long-term effects of early parental employment on children of the National Longitudinal Survey of Youth. Developmental Psychology, 35, $445-459$

Hill, C. R., \& Stafford, F. P. (1985). Parental care of children: Time diary estimates of quantity, predictability, and variety. In F. T. Juster \& F. P. Stafford (Eds.), Time, goods and well-being (pp. 415-438). Ann Arbor, MI: Institute for Social Research.

Hofferth, S. L., \& Sandberg, J. F. (2001). How American children spend their time. Journal of Marriage and Family, 63, 295-308.

Hoffman, L. W., \& Youngblade, L. M. (1999). Mothers at work: Effects on children's well-being. New York: Cambridge University Press.

Huston, A. C. (2002). Reforms and child development. Future of Children, 12, 59-78.

Juster, F. T. (1985). The validity and quality of time use estimates obtained from recall diaries. In F. T. Juster \& F. P. Stafford (Eds.), Time, goods, and well-being (pp. $63-$ 92). Ann Arbor, MI: Institute for Social Research.

Juster, F. T., \& Stafford, F. P. (Eds.). (1985). Time, goods, and well-being. Ann Arbor, MI: Institute for Social Research.

Kochanska, G., \& Thompson, R. A. (1997). The emergence and development of conscience in toddlerhood and early childhood. In J. Grusec \& L. Kuczynski (Eds.), Parenting and children's internalization of values: $A$ handbook of contemporary theory (pp. 53-77). New York: Wiley.

Lamb, M. E. (1997). Nonparental child care: Context, quality, correlates. In W. Damon (Series Ed.) \& I. E. Sigel \& K. A. Renninger (Vol. Eds.), Handbook of child psy- 
chology: Vol. 4. Child psychology in practice (5th ed., pp. 73-134). New York: Wiley.

Leibowitz, A. (1974). Education and home production. The American Economic Review, 64, 243-250.

National Institute of Child Health and Human Development Early Child Care Research Network. (1997a). The effects of infant child care on infant-mother attachment security: Results of the NICHD Study of Early Child Care. Child Development, 68, 860-879.

National Institute of Child Health and Human Development Early Child Care Research Network. (1997b). Familial factors associated with the characteristics of nonmaternal care for infants. Journal of Marriage and Family, 59, 389-408.

National Institute of Child Health and Human Development Early Child Care Research Network. (1998). Early child care and self-control, compliance and problem behavior at twenty-four and thirty-six months. Child Development, 69, 1145-1170.

National Institute of Child Health and Human Development Early Child Care Research Network. (1999). Child care and mother-child interaction in the first three years of life. Developmental Psychology, 35, 1399-1413.

National Institute of Child Health and Human Development Early Child Care Research Network. (2001). Child care and family predictors of preschool attachment and stability from infancy. Developmental Psychology, 37, $847-862$.

National Institute of Child Health and Human Development Early Child Care Research Network. (2003a). Does amount of time spent in child care predict socioemotional adjustment during the transition to kindergarten? Child Development, 74, 976-1005.

National Institute of Child Health and Human Development Early Child Care Research Network. (2003b). Early child care and mother - child interaction from 36 months through first grade. Infant Behavior and Development, 26, 345-370.

Nock, S. L., \& Kingston, P. W. (1988). Time with children: The impact of couples' work-time commitments. Social Forces, 67, 59-85.

Owen, M. T., \& Cox, M. J. (1988). Maternal employment and the transition to parenthood. In A. E. Gottfried \& A. W. Gottfried (Ed.), Maternal employment and children's development: Longitudinal research (pp. 85-119). New York: Plenum.

Owen, M. T., Easterbrooks, M. A., Chase-Lansdale, L., \& Goldberg, W. A. (1984). The relation between maternal employment status and the stability of attachments to mother and to father. Child Development, 55, 1894-1901.

Parcel, T. L., \& Menaghan, E. G. (1994). Early parental work, family social capital, and early childhood outcomes. American Journal of Sociology, 99, 972-1009.

Radloff, L. (1977). The CES-D scale: A self-report depression scale for research in the general population. Applied Psychological Measurement, 1, 385-401.

Reynell, J. (1991). Reynell Developmental Language Scales (U.S. ed.). Los Angeles, CA: Western Psychological Service.
Robinson, J. P. (1985). The validity and reliability of time use diaries versus alternative time use measures. In F. T. Juster \& F. P. Stafford (Eds.), Time, goods, and well-being (pp. 33-62). Ann Arbor, MI: Institute for Social Research.

Robinson, J. P., \& Godbey, G. (1997). Time for life: The surprising ways Americans use their time. University Park: Pennsylvania State University Press.

Schaeffer, E. S., \& Edgerton, M. (1985). Parent and child correlates of parental modernity. In I. E. Siegel (Ed.), Parental belief systems: The psychological consequences for children (pp. 297-318). Hillsdale, NJ: Erlbaum.

Schubert, J. B., Bradley-Johnson, S., \& Nuttal, J. (1980). Mother-infant communication and maternal employment. Child Development, 51, 246-249.

Schwartz, P. (1983). Length of day-care attendance and attachment behavior in eighteen-month-old infants. Child Development, 54, 1073-1078.

Sroufe, L. A. (1988). A developmental perspective on day care. Early Childhood Research Quarterly, 3, 283-291.

Stifter, C. A., Coulehan, C. M., \& Fish, M. (1993). Linking employment to attachment: The mediating effects of maternal separation anxiety and interactive behavior. Child Development, 64, 1451-1460.

Stith, S. M., \& Davis, A. J. (1984). Employed mothers and family day-care substitute caregivers: A comparative analysis of infant care. Child Development, 55, 1340-1348.

Thornburg, K. R., Pearl, P., Crompton, D., \& Ipsa, J. M. (1990). Development of kindergarten children based on child care arrangements. Early Childhood Research Quarterly, 5, 27-42.

Timmer, S. G., Eccles, J., \& O’Brien, K. (1985). How children use time. In F. T. Juster \& F. P. Stafford (Eds.), Time, goods, and well-being (pp. 353-382). Ann Arbor, MI: Institute for Social Research.

Vandell, D. L., \& Corasaniti, M. A. (1990). Child care and the family: Complex contributors to child development. New Directions for Child Development, 49, 23-37.

Vandell, D. L., \& Ramanan, J. (1992). Effects of early and recent maternal employment on children from lowincome families. Child Development, 63, 938-949.

Vaughn, B. E., Gove, F. L., \& Egeland, B. (1980). The relationship between out-of-home care and the quality of infant-mother attachment in an economically disadvantaged population. Child Development, 51, 1203-1214.

Waldfogel, J., Han, W., \& Brooks-Gunn, J. (2002). The effects of early maternal employment on child development. Demography, 39, 369-392.

Winer, B. J. (1971). Statistical principles in experimental design (2nd ed.). New York: McGraw-Hill.

Zaslow, M. J., Pederson, F. A., Suwalsky, J. T. D., Cain, R. L., \& Fivel, M. (1985). The early resumption of employment by mothers: Implications for parent-infant interaction. Journal of Applied Developmental Psychology, 6, 1-16.

Zaslow, M. J., McGroder, S. M., Cave, G., \& Mariner, C. L. (1999). Maternal employment and measures of children's health and development among families with some history of welfare receipt. In R. Hodson \& T. L. Parcel (Eds.), Research in the sociology of work: Vol. 7. Work and family (pp. 233-259). Stamford, CT: JAI Press. 